\title{
Improving Access and Quality of Health Care in the United States: Shared Goals Among Patient Advocates
}

\author{
Elisabeth M. Oehrlein ${ }^{1}$. Jason Harris ${ }^{1,2} \cdot$ Alan Balch $^{3} \cdot$ Pat Furlong $^{4} \cdot$ Eric Hargis $^{5} \cdot$ Mary Woolley $^{6} \cdot$ Eleanor Perfetto $^{1,7}$
}

Published online: 21 October 2020

(c) The Author(s) 2020

\section{Dear Editor,}

Dissatisfaction with past research and health care decision making that is not relevant or responsive to patient needs and preferences has led to a movement toward patient centricity in the US and around the world [1]. 'Patient centricity' and 'patient centeredness' broadly refer to any process, program or decision focused on patients in which patients play an active role as meaningfully engaged participants (not simply as study subjects) [2], and 'patient-centered health care' is defined as "care that is respectful of and responsive to individual patient preferences, needs, and values in the context of their own social worlds [3]." Patient centeredness is created by engaging, informing, and actively listening to people with chronic conditions at every point of contact-from the research bench to the bedside and everywhere in between [4]. This shift toward patient centricity has been exemplified by patient groups, professional organizations, as well as bodies such as the Patient-Centered Outcomes Research Institute (PCORI), who emphasize the importance of patientprioritized research questions in their funding decisions, and

Elisabeth M. Oehrlein

eoehrlein@nhcouncil.org

1 National Health Council, 1730 M St, Suite 500, Washington, DC, USA

2 Lupus Foundation of America, Inc., 2121 K Street NW, Suite 200, Washington, DC, USA

3 Patient Advocate Foundation, 1100 H St NW, Washington, DC, USA

4 Parent Project Muscular Dystrophy, 401 Hackensack Avenue, 9th Floor, Hackensack, NJ, USA

5 Colon Cancer Alliance, 1025 Vermont Ave NW Suite 1066, Washington, DC, USA

6 Research!America, 241 18th St S, Arlington, VA, USA

7 Department of Pharmaceutical Health Services Research, University of Maryland Baltimore, 220 Arch Street 12th floor, Baltimore, MD 21201, USA the US Food and Drug Administration's evolving patientfocused medical product development initiatives, such as the Patient-Focused Drug Development (PFDD) initiative and the Patient Engagement Advisory Committee (PEAC) for medical devices [5-7].

\section{Uptake of Patient Centricity in Research and Health Care Delivery is Uneven}

Despite calls for patient centricity across every sector of the health care ecosystem, uptake has been uneven. Although segments of the research and medical product development communities have fully embraced patient centricity, others have yet to systematically adopt patient engagement. For example, the US Food and Drug Administration recently released the first of four Patient-Focused Drug Development guidances [8]. The Council for International Organizations of Medical Sciences (CIOMS), known for their leadership in pharmacovigilance, established an Expert Working Group advancing patient involvement in drug development and safe use $[9,10]$. However, lack of consensus and other barriers continue to inhibit greater integration of patient insights across the medical product lifecycle [11].

Similarly, there is currently a limited role for patient engagement and slow movement towards patient centeredness in health care delivery. While Patient and Family Advisory Councils (PFACs) have been championed and established in some healthcare systems, uptake is inconsistent across facilities and has had unclear impact [12]. Patient groups in the US are particularly concerned over the lack of patient centricity in health care delivery and policy decisions impacting access to care [13-15].

In May 2017, a summit entitled "Forging a Sustainable Healthcare System" convened a diverse group of stakeholders to explore the dynamics of today's complex health care system and to co-create solutions to growing systemic challenges. The summit was supported by Amgen. This event 
assembled the leadership of 44 national patient advocacy organizations, professional societies, and research and public policy organizations, representing a variety of disease areas, to share perspectives on sustainable health care. Summit participants expressed a desire to continue the dialog started there and to work toward the shared goal of amplifying the patient's voice. As a result, a Task Force was formed with a multi-stakeholder group of 21 participating organizations. Over the course of 18 months, the Task Force worked to identify key principles describing the hallmark characteristics of patient centricity in biomedical research and the healthcare system that could be adopted to improve transparency, affordability, and access to care.

\section{Shared Goals to Improve Transparency, Affordability, and Access to Care}

\subsection{System-Wide Transparency}

- Principle \#1: All forms of communication should be easily accessible and in language that is clear and easy to understand.

\subsection{Patient-Centricity and Transparency in Research}

- Principle \#2: Research study and clinical trial designs must include patient engagement to ensure resulting evidence reflects patient needs and expectations.

- Principle \#3: Value frameworks and resulting assessments must reflect the patient's voice, including consideration of patient experiences, preferences, and outcomes of importance to them.

- Principle \#4: All clinical outcome assessments (i.e., patient-, caregiver-, and clinician-reported outcomes) should address concepts patients identify as most important and be incorporated into quality improvement initiatives, medical product development, value assessment, and care delivery.

- Principle \#5: Collecting and sharing patient-centric data (with appropriate privacy protections) should be leveraged to support high-quality health care delivery, research, value assessment, medical product development, and policy efforts.

\subsection{Patient-Centricity and Transparency in Health Care Delivery}

- Principle \#6: Patients (and family caregivers) should be treated with dignity and respect throughout their health care experience.
- Principle \#7: Throughout the care journey, patients should be informed, in language they understand, about their coverage; how coverage and payment decisions are made and can be appealed; choice of providers and provider options; all treatment options (including nontreatment); the costs of their coverage and care; and provider incentives or restrictions that can influence practice patterns.

- Principle \#8: Care coordination is instrumental to ensuring patients understand treatment options and resources available, and to avoid inefficiencies in care.

- Principle \#9: Providers should discuss participation in research, including clinical trials, with patients as a routine part of providing health care. How research findings inform decision making should also be discussed.

- Principle \#10: Treatment decisions should be based on what patients, in consultation with their care team, determine will lead to their desired health outcomes and founded upon all available, sound scientific evidence.

- Principle \#11: Person-centered, shared decision making and goal-concordant care planning should be the standard, with appropriate resources and decision-support tools available to foster communication between the patient (and family) and care team about the patient's goals, values, and preferences.

- Principle \#12: Care delivery must consider not only the physical impact of disease but also mental, emotional, social, and behavioral determinants of health, and other social implications such as financial toxicity, transportation challenges, stigma, etc. These implications extend to caregivers, families, and communities.

- Principle \#13: Health professional education and continuing education should include curriculum on patientcentered care and research, shared decision making, and cultural competency.

- Principle \#14: All health care stakeholders, not just providers, need to be educated on effective ways to engage patients, communicate, be responsive to patient needs, and ensure appropriate care.

\subsection{Affordability and Access to Care}

- Principle \#15: All patients should have access to affordable and accessible care regardless of age, race, ethnicity, income, sexual orientation, health status, geographic location, etc. This is especially true for preventative, mental health, and other, often-neglected services.

- Principle \#16: Value-based care and payment models should include patient-centered quality and outcome measures to evaluate person-centered communication, shared decision-making, care coordination, and essential support services that align with patient needs and values. 
- Principle \#17: Health care coverage and reimbursement decision making should be evidence based.

- Principle \#18: Programs that assist patients and families who struggle to access and afford care should be strengthened and enhanced to improve reach, effectiveness, and efficiency.

\section{Discussion}

The Task Force has identified timely, but also enduring principles that offer a foundation for activities that can be undertaken to amplify and elevate the patient voice across the healthcare ecosystem. We acknowledge, however, that achieving all 18 principles is an ambitious goal, particularly in the short term. While one organization or group of stakeholders may not be able to individually achieve implementation of each and every principle, it is valuable for relevant stakeholders to consider which actionable principles can serve as a starting point for collaborative efforts in the short term that can have impact for patients. It would be important to consider those principles that are highest priority but also have cross-cutting interest among groups that could be the focus of collaborative efforts and a coordinated plan of action.

Of note, the characteristic considered to be highest priority by the Task Force is ensuring patients have access to transparent information regarding their care and coverage. Without full transparency to all parties, the patient voice is muted, partially or fully, and cannot be effective. For example, a lack of transparency about treatment options prevents patients from making informed choices. Their individual voices, related to their preferences for treatment and outcomes, are lost. Likewise, a hospital that does not share information about quality issues with its PFAC does not benefit from the PFAC's perspective, potentially resulting in inappropriate or inefficient solutions. Patient groups should consider collaborative activities to encourage adoption of polices that improve transparency in care, coverage, and cost information. Partnerships between patients and multi-stakeholder groups can convey the message that greater transparency is needed across the board for the patient voice to be amplified.

The principles as a whole are largely consistent with recommendations and good practices put forth by other stakeholder groups. One such example is the Institute for Healthcare Improvement's Triple Aim - a set of intertwined goals to improve health care in the US that includes improving the experience of care, improving the health of populations, and reducing per-capita costs of health care. The Triple Aim has already been adopted by a number of health care systems, hospitals, and health insurance companies [16, 17], and identifying these synergies and partnering across stakeholder groups will be necessary to advance the principles in a realistic manner. As the patient community continues to advocate for the prioritization of the patient voice, the recommended principles are a lens from which one can view multi-stakeholder collaboration and engagement toward a patient-centered health ecosystem.

Acknowledgements Mary Franklin, MA, National Headache Foundation. Kathleen Gallagher, MPH, Patient Advocate Foundation. Claire Gill, National Osteoporosis Foundation. Patricia Goldsmith, CancerCare. Linda House, RN, BSN, MSM, Cancer Support Community. Norm Linsky, Mended Hearts. Steven Newmark, JD, MPA, Global Healthy Living Foundation. Gary Puckrein, PhD, National Minority Quality Forum. Elizabeth A. Thompson, National Osteoporosis Foundation. Pam Traxel, American Cancer Society Cancer Action Network, Inc. Silke Schoch, National Health Council. Andrea J. Singer, MD, FACP, CCD, Georgetown University Hospital. Sara Traigle van Geertruyden, JD, Partnership to Improve Patient Care. Stacey Worthy, JD, Aimed Alliance.

\section{Declarations}

Funding Amgen provided funding for the Summit described in this manuscript. Amgen staff did not have any role in content development or manuscript preparation, and did not take part in meetings, survey preparation, data analysis, and/or interpretation. Content development was led by the Steering Committee with input from the Task Force. The National Health Council was engaged by Amgen to lead manuscript development with direction from the broader Steering Committee. EO, $\mathrm{JH}$ (formerly), and EP are employees of the National Health Council, which is a not-for-profit membership organization. It is supported through membership dues and sponsorship funds. The complete list of members and sponsors is located on the website at www.nationalhe althcouncil.org. JH worked at the National Health Council at the time of the development of this document. He is currently an employee of the Lupus Foundation of America and has no conflicts of interest to report. EP is also part-time faculty at the University of Maryland Baltimore School of Pharmacy. EP has received research funding from the Food and Drug Administration, Excerpta Medica, Pfizer, Merck and Co, PhRMA. AB is currently an employee of the Patient Advocate Foundation, and has no conflicts of interest to report related to the content or development of this Letter to the Editor. PF is the founding president of Parent Project Muscular Dystrophy and has no conflicts of interest to report. EH is an employee of the Colon Cancer Alliance and has no conflicts of interest to report. MW is an employee of Research!America and has no conflicts of interest to report.

Open Access This article is licensed under a Creative Commons Attribution-NonCommercial 4.0 International License, which permits any non-commercial use, sharing, adaptation, distribution and reproduction in any medium or format, as long as you give appropriate credit to the original author(s) and the source, provide a link to the Creative Commons licence, and indicate if changes were made. The images or other third party material in this article are included in the article's Creative Commons licence, unless indicated otherwise in a credit line to the material. If material is not included in the article's Creative Commons licence and your intended use is not permitted by statutory regulation or exceeds the permitted use, you will need to obtain permission directly from the copyright holder. To view a copy of this licence, visit http://creativecommons.org/licenses/by-nc/4.0/. 


\section{References}

1. Institute of Medicine (US) Committee on Quality of Health Care in America. Crossing the Quality Chasm: A New Health System for the 21st Century [Internet]. Washington (DC): National Academies Press (US); 2001. https://www.ncbi.nlm.nih.gov/books /NBK222274/. Accessed 18 Dec 2018.

2. National Health Council, Genetic Alliance. Patient-Focused Drug Development-Recommended Language for Use in Guidance Document Development [Internet]. https://nationalhealthcounci 1.org/wp-content/uploads/2019/12/NHC-GA\%20Feb2017.pdf.

3. National Health Council. Glossary of Patient Engagement Terms. Available from: https://nationalhealthcouncil.org/glossary-ofpatient-engagement-terms/.

4. Epstein RM, Street RL. The values and value of patient-centered care. Ann Fam Med. 2011;9:100-3.

5. Forsythe L, Heckert A, Margolis MK, Schrandt S, Frank L. Methods and impact of engagement in research, from theory to practice and back again: early findings from the Patient-Centered Outcomes Research Institute. Qual Life Res. 2018;27:17-311.

6. Center for Drug Evaluation and Research (CDER). Patient Engagement Advisory Committee [Internet]. FDA. 2019. https ://www.fda.gov/advisory-committees/committees-and-meetingmaterials/patient-engagement-advisory-committee. Accessed 24 May 2019.

7. Perfetto EM, Burke L, Oehrlein EM, Epstein RS. Patient-focused drug development: a new direction for collaboration. Med Care. 2015;53:9-17.

8. Food and Drug Administration. FDA Patient-Focused Drug Development Guidance Series for Enhancing the Incorporation of the Patient's Voice in Medical Product Development and Regulatory Decision Making. FDA [Internet]. 2019. drugs/development-approval-process-drugs/ fda-patient-focused-drug-development-guidance-series-enhancing-incorporation-patients-voice-medical. Accessed 29 Apr 2019.

9. Council for International Organizations of Medical Sciences. Working Group XI-Patient Involvement in the Development and Safe Use of Medicines [Internet]. COUNCIL FOR INTERNATIONAL ORGANIZATIONS OF MEDICAL SCIENCES. https ://cioms.ch/working-groups/working-group-xi-patient-involvemen $\mathrm{t} /$. Accessed 11 June 2020

10. Pitts PJ. Towards meaningful engagement for the patient voice. Patient. 2019;12:361-3.

11. Janssens R, Russo S, van Overbeeke E, Whichello C, Harding $\mathrm{S}$, Kübler J, et al. Patient preferences in the medical product life cycle: what do stakeholders think? Semi-structured qualitative interviews in Europe and the USA. Patient. 2019;12:513-26.

12. Patient and Family Advisory Program Annual Reports [Internet]. https://www.ipfcc.org/bestpractices/pfa-annual-reports.html. Accessed 18 Dec 2018.

13. Perfetto EM, Oehrlein EM, Boutin M, Reid S, Gascho E. Value to whom? The patient voice in the value discussion. Value Health. 2017;20:286-91.

14. 041718 Letter to Hill on STLDPs Sign On-SIGNED FINAL_0. pdf [Internet]. https://nationalhealthcouncil.org/wp-content/ uploads/2019/12/041718\%20Letter\%20to\%20Hill\%20on\%20 STLDPs\%20Sign\%20On\%20-\%20SIGNED\%20FINAL.PDF. Accessed 19 Dec 2018.

15. The Roadmap Model [Internet]. National Patient Advocate Foundation. https://www.npaf.org/roadmap/the-roadmap-model I. Accessed 19 Dec 2018.

16. Whittington JW, Nolan K, Lewis N, Torres T. Pursuing the triple aim: the first 7 years. Milbank Q. 2015;93:263-300.

17. Berwick DM, Nolan TW, Whittington J. The triple aim: care, health, and cost. Health Aff (Millwood). 2008;27:759-69. 